\title{
SISTEM PENAMAAN ORANG BALI
}

\author{
I Gede Bagus Wisnu Bayu Temaja \\ Ilmu Linguistik, Fakultas Ilmu Budaya, Universitas Gadjah Mada \\ Email:wisnubt@gmail.com
}

\begin{abstract}
This research belonged to the field of anthropological linguistics. This research aimed atexplaining the naming system of Balinese people.Based on several previous studies, this research focused on the system of Balinese people's name in general.It was an anthropological linguistic research concerned on the relation between lingual aspects in the form of naming system and its cultural relations of the Balinese society. The research methodology was conducted into three steps, consist of: 1) data collection which was conducted by implementing interview method through recording and taking a note techniques, as well as literature-based research method; 2) data analysis which was conducted by implementing qualitative approach of interactive model; 3) data display which was conducted by explaining the data informally and displaying it on the table. The results show that there are three aspects that influence naming system of Balinese people, such as 1) sex, 2) birth order, and 3) caste system. Those aspects provided framework related to reference of Balinese name. This results reflect that the lingual aspect of naming system is influenced by cultural aspects, and therefore it represents the Balinese culture itself.
\end{abstract}

Keywords: naming system, Balinese people, anthropological linguistics

\section{Pendahuluan}

Nama menjadi suatu identitas diri yang paling pertama diperoleh seseorang sewaktu lahir. Menurut Hudson (1980: 122), nama diri merupakan pemarkah linguistik paling jelas dalam relasi sosial.Penamaan setiap orang dipengaruhi oleh beragam faktor seperti budaya, agama, bahasa, dan sebagainya. Menurut Basoeki (2014: 38), sistem penamaan dalam berbagai budaya dan masyarakat Indonesia berbeda, tata cara penamaan pun memiliki variasi tergantung dari asal pulau, suku, kebudayaan, bahasa, dan pendidikan yang diperoleh.

Tata cara penamaan seseorang dalam setiap budaya dan suku memiliki keunikannya tersendiri, seperti pada orang Bali yang memiliki keunikan karena dipengaruhi oleh beberapa aspek. Adapun beberapa contoh nama orang Bali seperti $I$ Putu Andika, Ni MadeDwi Ratri, I Gusti Bagus Alit, dan Anak Agung Sagung Rai. Dari nama-nama tersebut apakah terdapat 
aspek-aspek yang membedakan seperti nama keluarga, bentuk penghormatan, jenis kelamin, dan lainnya. Hal ini tentunya tidak akan sulit dijawab oleh orang Bali sendiri, tetapi tidak bagi masyarakat luar budaya Bali. Kita bisa juga melihat beberapa contoh sistem penamaan pada budaya lainnya di Indonesia, misalnya pada orang Jawa. Beberapa contoh nama dalam orang Jawa seperti Sumadi, Sutanto, dan sebagainya, memiliki penanda prefiks pada setiap awal nama mereka $\mathrm{Su}$-yang berarti baik. Sistem penamaan lainnya juga terdapat pada orang Buton yang menggunakan artikula $L a$ sebagai penanda laki-laki misalnya La Ode, dan $W a$ sebagai penanda perempuan, misalnya Wa Ode.

Penamaan seseorang di Bali dipengaruhi oleh beberapa aspek yang secara lingual tidak bisa dipecahkan tanpa mengetahui kebudayaannya. Untuk bisa mengungkap sistem penamaannya tersebut, maka perlu dilaksanakan suatu penelitian. Adapun yang dimaksud dengan orang Bali adalah suku Bali yang mendiami pulau Bali, dan daerah lainnya baik dalam maupun luar negeri. Berdasarkan pemaparan di atas, maka dapatlah ditarik suatu rumusan masalah dari penelitian ini, yaitu apakah aspek-aspek yang mempengaruhi sistem penamaan orang Bali?

Penelitian terkait penamaan orang Bali sudah pernah dilakukan. Salah satunya oleh Bandana (2015) yang menulis tentang "Sistem Nama Orang Bali: Kajian Struktur dan Makna”. Dalam penelitiannya tersebut, Bandana menggolongkan penamaan orang Bali menjadi tiga jenis struktur kata, yaitu kata sandang atau artikula, kata sifat, dan kata bilangan.Kemudian, Budi (2012) dalam artikel yang dimuat di laman internet berjudul "Budaya Bali: Nama Orang Bali" di mana dia memaparkan bahwa penamaan orang Bali dipengaruhi oleh jenis kelamin, urutan kelahiran, dan sistem kasta. Namun, tulisannya tersebut masih belum komprehensif dan sistematis. Berangkat dari penelitian dan tulisan tersebut yang hanya mengangkat dari segi kebahasaannya, maka penelitian ini ingin melengkapi sistem penamaan orang Bali yang secara kebahasaan dikaitkan dengan bidang kebudayaan.

Berdasarkan tinjauan pustaka tersebut, untuk menjalankan penelitian ini, 
peneliti menerapkan teori linguistik antropologi. Linguistik antropologi menitikberatkan pada hubungan antara bahasadan kebudayaan di dalam suatu masyarakat (Sibarani, 2004: 50). Istilah lain dari bidang ini yaitu linguistik budaya oleh Palmer (1996: 36). Linguistik budaya adalah sebuah disiplin ilmu yang muncul sebagai persoalan dari ilmu antropologi yang merupakan perpaduan dari ilmu bahasa dan budaya. Pada kajian ini, aspekaspek lingual yang berupa penamaan tersebut dikaitkan dengan kebudayaan yang ada di Bali sehingga aspek-aspek dalam sistem penamaan ini bisa ditemukan dan kemudian membuktikan bahwa penamaan tersebut menjadi representasi budaya masyarakat Bali

\section{Metode Penelitian}

Secara garis besar, metode penelitian ini dibagi menjadi tiga tahapan, yaitu: (1) penyediaan data, (2) analisis data, dan (3) penyajian data. (1) Penyediaan data dilaksanakan dengan menerapkanmetode cakap dengan teknik rekam dan catat (Sudaryanto, 1993: 137-139), dan metode studi pustaka. Data penelitianini berupa nama-nama orang Bali berikut kesejarahannya yang diperoleh dari informan yang terdiri dari informan primer dan sekunder. Informan primer merupakan informan utama yang menyediakan data, yaitu satu orang pemangku (pendeta Hindu). Informan sekunder merupakan informan tambahan yang memberikan data pendukung. Terdapat dua informan sekunder, yaitu satu orang kelian adat (tetua adat) dan satu orang kelian dinas (tetua urusan di luar adat). Selain itu, data juga diperoleh data diperoleh berdasarkan pengalaman dan pengetahuan pribadi peneliti yang merupakan suku Bali. (2) Analisis data dilaksanakan dengan menerapkan pendekatan kualitatif model interaktif Miles dan Huberman (1994), dengan prosedur: 1) pengumpulan data, 2) penyusutan data, 3) penyajian data, dan 4)penarikan kesimpulan.(3) Tahap penyajian data dilaksanakan secara informal dengan memaparkan hasil dari analisis data secara jelas dan rinci (Sudaryanto, 1993: 145), serta penyajian data menggunakan tabel.

\section{Hasil dan Pembahasan}

Berdasarkan data yang diperoleh, penamaan orang Bali berkaitan dengan tiga aspek, antara lain jenis kelamin, urutan kelahiran, dan sistem kasta.Adapun ketiga aspek tersebut dipaparkan sebagai berikut. 


\subsection{Jenis Kelamin}

Penanda penamaan dalam aspek jenis kelamin ini menjadi yang palingmudah diidentifikasi pada nama orang Bali. Secara sederhana, penggunaan aspek penanda ini dipergunakan sebagai nama depan. Penggolongan nama dengan aspek yang paling umum yaitu penggunaan artikula $I$ dan $N i$. Artikula $I$ merupakan pemarkah nama laki-laki, sedangkan artikula $\mathrm{Ni}$ merupakan pemarkah nama perempuan (Budi, 2012). Dalam penanda jenis kelamin ini ditemukan beberapa kasus. Beberapa contoh nama dengan artikula $I$ dan $N i$ sebagai berikut.

Tabel 1. Nama Berdasarkan Penanda I dan Ni

\begin{tabular}{|l|l|}
\hline \multicolumn{1}{|c|}{ Nama } & Jenis Kelamin \\
\hline I Gede Putra & Laki-laki \\
\hline I Wayan Dana & Laki-laki \\
\hline Ni Ketut Rutmini & Perempuan \\
\hline Ni Nengah Dwi Antari & Perempuan \\
\hline
\end{tabular}

Pada nama seseorang dari kasta Brahmana (bahasan spesifik tentang kasta akan dibahas di bagian akhir), artikula nama depan seseorang dari golongan tersebut diberikan gelar Ida. Artikula ini merupakan bentuk honorifik dari artikula $I$.
Pada kasta ini, untuk membedakan penggolongan berdasarkan jenis kelamin umumnya diikuti pemarkah nama Bagus dan $A y u$ setelah artikula Ida tersebut.Nama Bagus berarti 'rupawan' diberikan kepada laki-laki,dan $А y u$ berarti 'jelita' diberikan kepada perempuan. Sangat jarang ditemui nama seorang Brahmana yang hanya diberikan artikula $I d a$ tanpa diikuti nama pemarkah jenis kelamin Bagus dan Ayu tersebut (Budi, 2012). Beberapa contoh nama dalam kasus ini.

Tabel 2. Nama Berdasarkan Penanda Bagus dan $A y u$

\begin{tabular}{|l|l|}
\hline \multicolumn{1}{|c|}{ Nama } & \multicolumn{1}{c|}{ Jenis Kelamin } \\
\hline Ida Bagus Mantra & Laki-laki \\
\hline Ida Bagus Oka & Laki-laki \\
\hline Ida Ayu Ratih & Perempuan \\
\hline Ida Ayu Putri & Perempuan \\
\hline
\end{tabular}

Pada kalangan kasta Kesatria, hampir sama seperti penamaan kasta Brahmana yang diberikan artikula Ida sebagai nama depan, akan tetapi penanda jenis kelamin yang mengikuti artikula tersebut berbeda. Pada kasta ini, penanda laki-laki diikuti oleh gelar yang salah satunya Cokorda sehingga menjadi Ida Cokorda. Tetapi, penanda nama pada perempuan memiliki beberapa variasi dan 
aturannya tersendiri, seperti Istri dan Sagung. Nama seorang perempuan yang bergelar Cokorda umumnya tidak lagi diawali oleh artikula Ida di awal nama, namun diikuti oleh penanda jenis kelamin Istri. Penanda Sagung mengikuti gelar lainnya pada kasta Kesatria, misalnya Anak Agung. Lebih lanjut, khusus untuk nama Sagung bisa berfungsi sebagai artikula dengan diikuti oleh penanda Istri. Beberapa contoh nama kasus ini sebagai berikut.

Tabel 3. Nama Berdasarkan Gelar Ida Cokorda, Cokorda Istri, dan Sagung

\begin{tabular}{|l|l|}
\hline \multicolumn{1}{|c|}{ Nama } & \multicolumn{1}{|c|}{$\begin{array}{c}\text { Jenis } \\
\text { Kelamin }\end{array}$} \\
\hline $\begin{array}{l}\text { Ida Cokorda Anglurah } \\
\text { Tabanan XXIV }\end{array}$ & Laki-laki \\
\hline Ida Cokorda Malkangin & Laki-laki \\
\hline $\begin{array}{l}\text { Cokorda Istri Krisnanda } \\
\text { Widani }\end{array}$ & Perempuan \\
\hline Sagung Istri Pramita & Perempuan \\
\hline
\end{tabular}

Pada variasi lain, penamaan berdasarkan jenis kelamin bisa ditemukan pada nama seseorang dari kasta Sudra. Namun, yang diberikan penanda variasi tersebut hanyalah perempuan dengan penanda nama Luh yang berarti 'perempuan'. Penamaan ini lazimnya bisa atau tanpa diawali artikula $N i$, dan dengan atau tanpa diikuti oleh penanda nama umum, seperti Made, Komang, Ketut, dan sebagainya (akan dibahas pada pemaparan selanjutnya), atau tanpa keduanya. Khusus untuk nama perempuan yang diberikan nama Gede sifatnya wajib untuk diawali oleh nama $L u h$, namun artikula $N i$ sifatnya opsional. Berikut beberapa contoh nama dari kasus ini.

Tabel 4. Nama Berdasarkan Penanda Luh

\begin{tabular}{|c|c|}
\hline Nama & Jenis Kelamin \\
\hline $\begin{array}{l}\text { Ni Luh Made Sri } \\
\text { Utami }\end{array}$ & Perempuan \\
\hline Ni Luh Sri Utami & Perempuan \\
\hline Luh Made Sri Utami & Perempuan \\
\hline Luh Sri Utami & Perempuan \\
\hline $\begin{array}{l}\text { Ni Luh Gede Eka } \\
\text { Murtini }\end{array}$ & Perempuan \\
\hline $\begin{array}{l}\text { Luh Gede Eka } \\
\text { Murtini }\end{array}$ & Perempuan \\
\hline
\end{tabular}

Hasil analisis penamaan berdasarkan jenis kelamin ini sejalan dengan penelitian Bandana (2015: 4) yang menyebutkan bahwa artikula $I$ dan $\mathrm{Ni}$ masing-masing merupakan penanda lakilaki dan perempuan dan umumnya diberikan pada awal nama seseorang. 
Terkait penamaan Bagus dan Ayu tersebut dalam penelitian Bandana (2015: 5) masing-masing merupakan penanda lakilaki dan perempuan, tetapi dalam penelitian tersebut kasus ini secara struktur kebahasaan diklasifikasikan ke dalam kata sifat.

\subsection{Urutan Kelahiran}

Penamaan menurut aspek ini menjadi suatu keunikan yang berbeda dengan budaya lain.Aspek ini menjadi penanda seseorang tersebut merupakan anak urutankeberapa. Secara garis besar menurut "Sastra Kanda Pat Sari" dalam Budi (2012), terdapat empat macam penamaan berdasarkan urutan kelahiran masing-masing dari yang tertua sampai termuda, yaitu Wayan, Made, Nyomanatau Komang, dan Ketut. Namanama tersebut dianggap sebagai nama dasar dan beberapamemiliki variasinya masing-masing. Selain itu akan dikaitkan juga dengan jenis kelamin dan sistem kasta pada masing-masing nama, serta kasus unik mengenai penamaan berdasarkan aspek ini.

\subsubsection{Wayan}

Nama ini merupakan nama untuk anak pertama. Wayan berasal dari kata 'wayah' yang berarti 'tua' (Budi, 2012). Variasi lain nama ini yaitu Putu dan Gede. Putuberarti 'cucu' dan Gede berarti 'besar'. Pada aspek jenis kelamin, nama Wayan dan Putu bisa diberikan kepada laki-laki dan perempuan. Sedangkan nama Gede umumnya diberikan kepada laki-laki, tetapi bisa juga diberikan kepada perempuan jika namanya sudah didahului penanda $L u h$. Pada aspek kasta, nama Putu lebih cenderung dipilih oleh kalangan diatas kasta Sudra. Beberapa contoh nama dari penanda ini sebagai berikut.

Tabel 5. Nama Anak Pertama

\begin{tabular}{|l|l|}
\hline \multicolumn{1}{|c|}{ Nama } & Jenis Kelamin \\
\hline I Wayan Adi Bawa & Laki-laki \\
\hline Ni Putu Eka Wiryastuti & Perempuan \\
\hline I Gede Anggara Yasa & Laki-laki \\
\hline Luh Gede Kurniawati & Perempuan \\
\hline
\end{tabular}

\subsubsection{Made}

Nama ini diberikan kepada anak kedua. Made berasal dari kata Madya yang berarti 'tengah' (Budi, 2012). Variasi lain dari nama ini adalah Nengah dan Kadek atau Kade. Nengah sendiri berasal dari kata 
'tengah' menurut (Budi, 2012). Lebih lanjut, Kadek atau Kade berasal dari kata adi yang berarti 'adik' yang dimana secara diakronis perubahan adi menjadi variasi tersebut bisa dilacak. Pada aspek jenis kelamin, nama-nama tersebut dapat diberikan kepada laki-laki dan perempuan. Pada aspek kasta, umumnya golongan di atas kasta Sudra hanya memilih Made dan Kade untuk penamaan. Adapun contohcontoh nama penanda ini dapat dilihat sebagai berikut.

Tabel 6. Nama Anak Kedua

\begin{tabular}{|l|l|}
\hline \multicolumn{1}{|c|}{ Nama } & Jenis Kelamin \\
\hline I Made Mangku Pastika & Laki-laki \\
\hline Ni Nengah Dwi Arianti & Perempuan \\
\hline $\begin{array}{l}\text { I Kadek Bagus Darma } \\
\text { Winatha }\end{array}$ & Laki-laki \\
\hline I Gusti Kade Oka & Laki-laki \\
\hline
\end{tabular}

\subsubsection{Nyoman atau Komang}

Salah satu nama tersebut diberikan kepada anak ketiga. Ada beberapa asumsi dan hipotesa terkait asal-usul nama tersebut berdasarkan beberapa informan dan pustaka. Menurut Budi (2012), Nyoman berasal dari kata anom yang berarti 'muda' atau 'kecil', dan Komang merupakan bentuk variasinya. Lebih lanjut, Budi menganggap bahwa Nyoman berasal dari kata nyeman yang berarti 'lebih tawar', hal ini berkaitan dengan kulit terluar pohon pisang yang rasanya tawar. Anggapan tersebut ada dasarnya karena orangBali memiliki kedekatan kebudayaan dengan pohon pisang. Mereka mengonsumsi batang muda pohon pisang setelah diolah menjadi jukut ares (semacam masakan sayur berkuah berisi rebusan potonganpotongan batang muda pohon pisang tersebut), jika hanya dimakan biasa setelah direbus maka rasanya tawar. Nama Nyoman dan Komang berasal dari kata uman yang berarti 'sisa' (Budi, 2012). Dari aspek jenis kelamin dan kasta, keduanya memakai penanda nama ini tanpa ada aturan-aturan spesifik. Berikut beberapa nama seseorang dari penanda ini.

Tabel 7. Nama Anak Ketiga

\begin{tabular}{|c|c|}
\hline Nama & Jenis Kelamin \\
\hline Ni Komang Wedri & Perempuan \\
\hline I Nyoman Wibisana & Laki-laki \\
\hline $\begin{array}{l}\text { Gusti Komang } \\
\text { Widana }\end{array}$ & Laki-laki \\
\hline
\end{tabular}

Dari perspektif penulis terkait asalusul nama tersebut yang berkaitan dengan muda, kecil, lebih tawar, dan sisa, 
semuanya berasosiasi pada sesuatu hal yang sifatnya akhir. Ada anggapan bahwa dahulu masyarakat Bali biasa memiliki tiga anak. Masyarakat Bali berpatokan pada jumlah tiga karena angka tersebut identik dengan konsep-konsep teologi Hindu Bali yang didasari pada hal yang terdiri dari tiga atau tri, seperti Tri Datu, Tri Hita Karana, Tri Murti, Tri Kaya Parisudha, dan sebaginya (lihat Eiseman, 2000). Berpatokan dari hal itu maka dapat disimpulkan bahwa Nyoman atau Komang tersebut berarti sesuatu yang berada di akhir (muda). Hal ini juga akan didukung oleh asal-usul nama Ketut (akan dijelaskan selanjutnya).

\subsubsection{Ketut}

Nama ini diberikan untuk menamai anak keempat yang berasal dari kata ketuut yang berarti 'mengikuti' atau 'membuntuti' (Budi, 2012). Penamaan ketuut berkaitan dengan penamaan Nyoman atau Komang karena dahulu orang Bali berpatokan pada tiga orang anak untuk penamaan anak, sehingga nama Nyoman atau Komang menjadi yang terakhir. Tetapi kemudian anak yang keempat muncul yang secara simultan terjadi di banyak keluarga sehingga diperlukan penamaan untuk anak ini. Karena anak keempat ini sifatnya mengikuti untuk lahir walau 'tidak diinginkan' sehingga dinamai ketuwut dalam Bahasa Bali (membuntuti atau mengikuti). Tidak ada variasi lain dari nama ini yang memperkuat asumsi, bahwa secara diakronis nama ini tergolong 'baru/muda' dibandingkan tiga lainnya. Terkait dengan jenis kelamin dan penggunaannya dalam kasta, tidak ada aturan khusus sama seperti penamaan Nyoman atau Komang. Berikut beberapa contoh nama dari penanda ini.

Tabel 8. Nama Anak Keempat

\begin{tabular}{|l|l|}
\hline \multicolumn{1}{|c|}{ Nama } & \multicolumn{1}{c|}{ Jenis Kelamin } \\
\hline I Ketut Jaya & Laki-laki \\
\hline Ni Ketut Ari Pratiwi & Perempuan \\
\hline Ida Ayu Ketut Tari & Perempuan \\
\hline
\end{tabular}

Terdapat kasus yang wajib diperhatikan dalam penamaan aspek ini. Untuk keluarga yang memiliki anak lebih dari empat, maka penamaan mereka akan diulang kembali ke penamaan awal/pertama. Secara umum, anak ke lima akan diberikan penamaan pertama, anak keenam akan diberikan penamaan kedua, 
dan seterusnya. Berikut penanda dan aturan khusus (1), (2), dan (3) untuk penamaan kasus ini secara spesifik.

(1) Pemberian nama tengah Alit yang berarti 'kecil', misalnya I Putu Alit Dana (anak ke lima, Ni Made Alit Restini (anak ke enam), dan seterusnya.

(2) Pemberian nama menurut urutan angka Bahasa Jawa Kuno dalam nama tengah $($ Panca $=$ anak kelima, Sad $=$ anak keenam, sapta $=$ anak ketujuh, asta $=$ anak kedelapan, dan seterusnya), misalnya I Wayan Panca Putra.

(3) Dalam sapaan diberikan tambahan sebutan Balik yang berarti 'kembali' mengikuti nama berdasarkan urutan kelahiran. Misalnya, sapaan Putu Balik untuk anak kelima, Made Balik untuk anak keenam, dan seterusnya.

Terkait dengan penamaan kasus (2) di atas yang berdasarkan urutan angka Bahasa Jawa Kuno yang dimana bukti tersebut mendukung penelitian dari Bandana (2015: 5). Secara berurutan dari anak tertua sampai terkecil diberikan nama Eka, Dwi, Tri, Catur, Panca, dan seterusnya sebagai bagian dari nama seseorang.

\subsection{Sistem Kasta}

Aspek ketiga ini bisa dibilang merupakan aspek terumit dalam pemberian nama seseorang karena terdapat berbagai aturan dan variasi untuk masing-masing kasta. Saat ini, pengertian tentang kasta menjadi sebuah perdebatan serius dari berbagai kalangan dalam masyarakat Bali. Namun, disini peneliti berpegangan pada pengertian sistem kasta yang merupakan golongan sosial terdiri dari Brahmana, Kesatria, Waisya, dan Sudra. Keempat golongan tersebut disebut dengan catur wangsa, catur warna, atau kasta (Wiana, 2006: 10). Penggolongan pada umumnya disebut catur warna, catur wangsa,catur jatma/janma (Agung, 2001: 45). Untuk pengertian lebih mendalam tentang asalusul dari kasta ini tidak akan dibahas karena penelitian ini lebih menitikberatkan pada macam-macam penamaan berdasarkan aspek ini.

\subsubsection{Brahmana}

Kalangan ini merupakan keturunan pemuka agama pada jaman kerajaan dahulu dan dipercaya untuk memimpin 
upacara keagamaan. Tempat kediaman mereka dikenal dengan sebutan griya yang sudah diwariskan secara turun-temurun. Namun saat ini tidak semua keturunan ini menjalankan profesi di bidang keagamaan dan tinggal di griya tersebut. Terkait penamaan, umumnya golongan ini memiliki penanda dengan gelar Ida Bagus untuk laki-laki dan Ida $A y u$ (biasa disingkat Dayu) untuk perempuan (Budi, 2012). Berikut merupakan beberapa contoh penamaan dari gelar tersebut.

Tabel 9. Penamaan Kasta Brahmana

\begin{tabular}{|l|l|}
\hline \multicolumn{1}{|c|}{ Nama } & \multicolumn{1}{c|}{ Jenis Kelamin } \\
\hline Ida Bagus Arya & Laki-laki \\
\hline IdaBagus Rai Krisna & Laki-laki \\
\hline Ida Ayu Candra Dewi & Perempuan \\
\hline Ida Ayu Nyoman Rai & Perempuan \\
\hline
\end{tabular}

\subsubsection{Kesatria}

Golongan ini merupakan para keturunan raja, bangsawan, dan pejabat setingkat lainnya pada jaman kerajaan dahulu. Mereka tinggal di kediaman yang disebut puri yang sudah diwariskan turun-temurun. Dengan berkembangnya jaman, sebagian dari mereka sudah tidak menetap lagi di puri, dan pekerjaan mereka juga beragam.
Terkait penamaan, umumnya mereka mempunyai gelar seperti Anak Agung (disingkat Gung), Cokorda (disingkat Cok), atau Gusti. Dalam golongan ini juga ditemui gelar lain seperti Dewa atau Dewa Ayu, Desak, dan Sagung. Tiga gelar terakhir hanya diberikan kepada perempuan. Adapun ragam nama-nama seseorang untuk gelar ini sebagai berikut.

Tabel 10. Penamaan Kasta Kesatria

\begin{tabular}{|c|c|}
\hline Nama & Jenis Kelamin \\
\hline $\begin{array}{l}\text { Anak Agung Bagus } \\
\text { Sutedja }\end{array}$ & Laki-laki \\
\hline $\begin{array}{l}\text { Cokorda Gde Agung } \\
\text { Sukawati }\end{array}$ & Laki-laki \\
\hline I Gusti Putu Martha & Laki-laki \\
\hline Dewa Made Beratha & Laki-laki \\
\hline $\begin{array}{l}\text { Dewa Ayu Dwi } \\
\text { Maharani }\end{array}$ & Perempuan \\
\hline $\begin{array}{l}\text { DesakMade Hughesia } \\
\text { Dewi }\end{array}$ & Perempuan \\
\hline
\end{tabular}

\subsubsection{Waisya}

Kalangan ini merupakan keturunan pengusaha, pedagang, dan juragan pada jaman kerajaan. Sekarang profesi mereka sudah beragam, seperti pada keturunan 
kasta lainnya yang sebagian besarsudah tidak melanjutkan profesi leluhurnya. Golongan ini umumnya bergelar Ngakan, Kompyang, Sang, dan Si. Saat ini, pemberian nama depan menggunakan gelar tersebut sudah sedikit ditemui. Mayoritas dari mereka memilih menanggalkan pemberian gelar tersebut pada keturunannya dan lebih memilih nama umum pada urutan kelahiran. Untuk menandai jenis kelamin, khusus untuk penanda perempuan umumnya diikuti oleh nama Ауи setelah gelar. Khusus untuk perempuan yang diberikan gelar $\mathrm{Si}$, biasanya diikuti oleh penanda jenis kelamin Luh yang bergabung membentuk Siluh. Untuk pemberian gelar Ngakan pada perempuan jarang ditemui. Berikut beberapa nama dari kasta ini.

Tabel 11. Penamaan Kasta Waisya

\begin{tabular}{|l|l|}
\hline \multicolumn{1}{|c|}{ Nama } & \multicolumn{1}{|c|}{$\begin{array}{c}\text { Jenis } \\
\text { Kelamin }\end{array}$} \\
\hline Ngakan Gede Sugiartha & Laki-laki \\
\hline Kompyang Ayu Sukarthi & Perempuan \\
\hline Kompyang Sujana & Laki-laki \\
\hline Sang Putu Suryanjaya & Laki-laki \\
\hline Sang Ayu Gita & Perempuan \\
\hline Si Arya Ketut & Laki-laki \\
\hline Siluh Made Desi Antari & Perempuan \\
\hline
\end{tabular}

\subsubsection{Sudra}

Golongan ini tidak memiliki gelar khusus sehingga memilih pemberian nama berdasarkan urutan kelahiran pada umumnya (Budi, 2012). Dahulu golongan ini merupakan para pekerja dan buruh, tetapi saat ini profesi mereka sudah beragam, mulai dari pemimpin daerah sampai pekerja biasa. Terkait pemaparan detail mengenai nama ini sudah dipaparkan banyak dan berikut merupakan beberapa contoh dari penamaan ini.

Tabel 12. Penamaan Kasta Sudra

\begin{tabular}{|l|l|}
\hline \multicolumn{1}{|c|}{ Nama } & \multicolumn{1}{c|}{ Jenis Kelamin } \\
\hline I Wayan Jaman & Laki-laki \\
\hline I Nengah Sudiana & Laki-laki \\
\hline Ni Nyoman Sri & Perempuan \\
\hline Ni Ketut Ratmi & Perempuan \\
\hline
\end{tabular}

Secara keseluruhan, aspek jenis kelamin, urutan kelahiran, dan sistem kasta memang menjadi suatu keunikan tertentu yang menandai bagaimana budaya Bali tersebut mempengaruhi aspek lingual penamaan. Hal ini sejalan dengan teori linguistik antropologi dimana aspek-aspek lingual yang berupa penamaan tersebut merupakan pemarkah suatu budaya (Sibarani, 2004: 50), serta data-data yang 
diperoleh mendukung pendapat dari Budi (2012). Hal itudisebut demikian karena penamaan-penamaan tersebut mencirikan budaya Bali. Dengan mengatakan salah satu contoh nama tersebut, misalnya Made, sudah barang jelas yang menjadi asosiasi adalah budaya Bali, walaupun yang bersangkutan tidak lahir dan menetap di Bali (misalnya orang Bali di tanah transmigrasi atau migrasi).

\section{Simpulan}

Berdasarkan pemaparan tersebut, secara garis besaraspek-aspek yang mempengaruhi sistem penamaan orang Bali dibedakan menjadi tiga, yaitu:

1) Penanda nama yang membedakan jenis kelamin antara laki-laki dan perempuan. Beberapa contohnya seperti pemberian artikula $I$ dan nama Bagus untuk menandai nama laki-laki. Artikula $N i$ dan nama $A y u$, Istri, dan Luh untuk menandai nama seorang perempuan.

2) Penamaan berdasarkan urutan kelahiran berikut dengan variasinya dibagi menjadi empat, yaitu: Wayan, Putu, dan Gede (anak pertama); Made, Nengah, dan
Kadek atau Kade (anak kedua); Nyoman atau Komang (anak ketiga); dan Ketut (anak keempat). Penamaan pada aspek ini bisa disebut sebagai nama umum dalam budaya penamaan orang Bali.

3) Penamaan berdasarkan empat sistem kasta, antara lain:Ida Bagus untuk laki-laki dan Ida Ayu untuk perempuan (Brahmana);Anak Agung, Cokorda,Gusti, dan Dewa untuk laki-laki dan perempuan, namun khusus Dewa Ayu, Desak, dan Sagung menandai perempuan (Kesatria); Ngakan, Kompyang, Sang, dan Si untuk laki-laki dan perempuan, namun khusus perempuan ditambahkan nama $A y u$ setelah gelar tersebut (Waisya); dan penamaan umum Wayan, Made, Nyoman atau Komang, dan Ketut (Sudra).

Melalui penelitian ini diharapkan mampu memberikan informasi signifikan bagi masyarakat secara umum. Bagi masyarakat Bali sendiri, penelitian ini memberikan refleksi tentang sistem penamaan yang perlahan tergerus jaman 
dan bahkan sudah ada yang sudah mulai menanggalkan sistem penamaan ini.

\section{Daftar Pustaka}

Agung, A.A. G. P. (2001). Perubahan Sosialdan Pertentangan Kasta di Bali Utara.Yogyakarta: Yayasan untuk Indonesia.

Bandana, I. G. W. S. (2015). Sistem Nama Orang Bali: Kajian Struktur dan Makna. Aksara, 27(1),1-11. Diambil darihttp://dx.doi.org/10.29255/aksara .v27i1.166.1-11

Basoeki, O. de H. (2014). Sistem Penamaan dalam Budaya Sabu. Epigram, 10 (1), 38-43.

Budi. (2012). Budaya Bali: Nama Orang Bali [Posting Laman]. Diambil dari http://cakepane.blogspot.co.id/2012/ 07/nama-orang-bali.html pada 13 Desember 2017.
Eiseman, F. B. (2000). Bali: Sekala \& Niskala. Hongkong: Periplus Edition.

Hudson, R. A. (1980). Sociolinguistics. Cambridge: Cambridge University Press.

Miles, M. B. \& Huberman, A. M. (1994). Qualitative Data Analysis. London: Sage Publications.

Palmer, G. B. (1996). Toward a Theory of Cultural Linguistics. Austin: The University of Texas Press.

Sibarani, R. (2004). Antropolinguistik: Antropologi Lingusitik, Linguistik Antropologi. Medan: Poda.

Sudaryanto. (1993). Metode dan Aneka Teknik Analisis Bahasa:Pengantar Penelitian Wahana Kebudayaan secara Linguistis. Yogyakarta: Duta Wacana University Press.

Wiana, I. K. (2006). Memahami Perbedaan Catur Warna,Kasta, dan Wangsa. Surabaya: Penerbit Paramita 